\title{
Influence of the Connector Area on the Chipping Rate of the VM9 Veneering Ceramic in a Posterior Four-Unit Yttria-Stabilized Tetragonal Zirconia Polycrystal Fixed Dental Prostheses: A Pilot Study
}

\author{
Camille Haddad ${ }^{1}$ Jean-Marc Meyer ${ }^{2}$ Mayssaê El Ahmadié ${ }^{3}$ \\ ${ }^{1}$ Department of Prosthodontics and Occlusion, Faculty of Dentistry, \\ Saint Joseph University, Beirut, Lebanon \\ 2 School of Dental Medicine, University of Geneva, Geneva, Switzerland \\ Address for correspondence Camille Haddad, DDS, MS, DEA, \\ Department of Prosthodontics and Occlusion, Saint Joseph University, \\ Beirut, Lebanon (e-mail: camhaddad@hotmail.com).
}

3 Private Practice, Beirut, Lebanon

Eur J Gen Dent 2021;10:144-150.

\begin{abstract}
Keywords

- chipping rate

- connector area

- four-unit fixed dental prosthesis

- sonographic technique

- static load bearing test

Objective The purpose of this study was to evaluate the influence of the connector area on the chipping rate of the VM9 veneering ceramic in a 4-unit yttria-stabilized tetragonal zirconia polycrystal (Y-TZP) framework, using a novel sonographic technique.

Materials and Methods The framework was designed as a 4-unit fixed dental prostheses (FDP) with two abutment teeth at the first mandibular premolar and second mandibular molar. The cross-sectional area of the connector was 7.5, 8, or $9 \mathrm{~mm}^{2}$. The prepared teeth were scanned using CAD/CAM technology, and five frameworks were prepared for each design, making a total of 15 . The frameworks were divided according to the veneering ceramics: Y-TZP FDPs using Vita VM9 (12 frameworks), and porcelain fused to metal (PFM) FDPs using Vita VM13 (3 frameworks). The specimens were statically loaded until failure. To capture the initiation of the failure within the specimens, a novel sonographic technique, designed for this research, combining acoustic emission and visual monitoring during live load bearing tests, was used to determine the failure load value. Failed frameworks were inspected using a microscope, and failure patterns were identified. One-way ANOVA and Tukey HSD tests were applied for statistical analysis of the results ( $p$-value $\leq 0.05$ ).

Results Despite the fact that the chipping strength is proportional to the crosssectional area of the connector, the effect of the cross-sectional area on chipping load revealed no statistically significant differences, while PFMs showed superior chipping strength relative to the zirconia frameworks regardless of the connector's size. A high rate of catastrophic fracture occurred while loading the specimens.

Conclusion The effect of the cross-sectional area on chipping load revealed no statistically significant differences in Y-TZP frameworks. The novel sonographic technique may be a potential method to study the behavior of dental ceramics, including chipping and fracture.
\end{abstract}

DOI https://doi.org/ $10.1055 / \mathrm{s}-0041-1736373$ ISSN 2278-9626.

\footnotetext{
(c) 2021. European Journal of General Dentistry. All rights reserved. This is an open access article published by Thieme under the terms of the Creative Commons Attribution-NonDerivative-NonCommercial-License, permitting copying and reproduction so long as the original work is given appropriate credit. Contents may not be used for commercial purposes, or adapted, remixed, transformed or built upon. (https://creativecommons.org/ licenses/by-nc-nd/4.0/)

Thieme Medical and Scientific Publishers Pvt. Ltd., A-12, 2nd Floor, Sector 2, Noida-201301 UP, India
} 


\section{Introduction}

Yttria-stabilized zirconia cores veneered with glass ceramics are being used nowadays as a replacement for metal and metal ceramic restorations, due to both the superior mechanical properties of the zirconia and the increased esthetic properties of the veneering ceramics. ${ }^{1,2}$ Yet, metal-ceramic fixed dental prostheses (FDPs) and zirconia monolithic restorations are still considered the standard treatment modalities in dental practice, and veneered zirconia restorations are not outdated.

The remarkable mechanical characteristics of yttria-stabilized tetragonal zirconia polycrystal (Y-TZP) (high-strength and fracture) make it an attractive core material for single and multiunit FDPs. The high-fracture resistance of the zirconia is due to the structural transformation when exposed to stress. In fact, this phase transformation produces a volume increase in the stress zone, which results in compressive stresses within the matrix, thereby hindering cracks from growing. ${ }^{3}$ In addition to material properties, the dimensional design of an FDP is important for the clinical outcome. Therefore, clinical recommendations for Y-TZPbased FDP connectors varied from 2 to $5 \mathrm{~mm}$ in height and width. $^{4}$

Despite mechanical properties, posterior zirconia restorations have showed a high rate of failures, which are related to cohesive fracture of the veneering ceramic (chipping). Chipping is defined as "a typical failure of contact loadings, normally produced when a crack generated or propagated by contact loads deflects due to the presence of a free surface nearby." ${ }^{5-7}$ It is known that cracks form and propagate when the tensile stress (external and residual stresses) within the ceramic exceeds the tensile strength. ${ }^{8,9}$ Residual stresses or "locked-in" stresses, present within the veneer and the framework, can cause immediate or delayed cracking of the ceramic. The cooling rate, the coefficient of thermal expansion (CTE) of the veneering ceramic, and the coreveneer thickness ratio have been reported to influence these stresses. $^{9-11}$

Several chipping factors have been proposed, including mechanical properties of the veneering materials, subcritical crack growth (SCG), thermal residual stresses, microscopic surface contact damages, influence of the restoration design, microstructural and compositional changes at the veneering ceramic/Y-TZP interface, microstructural defects generated during the manufacturing process, cementation techniques, and veneering materials and methods. ${ }^{12,13}$

The following classification of the ceramic fractures has been suggested: type 1 , crack of the veneering ceramic; type 2 , chipping restricted to the veneering ceramic; type 3 , chipping exposing the core; and type 4, fracture of the core. Moreover, these classifications can be divided into "non-critical" (reparation possibility) or "critical" (replacement necessity). ${ }^{14,15}$

Furthermore, different testing methods have been described to evaluate the problem of cracks and subcracks in dental ceramics. The crack detection in ceramic materials can be done using destructive testing or nondestructive testing
(NDT). These NDT methods include infrared and thermal testing, ultrasonic testing (UT), laser testing, radiographic testing, penetrant testing (PT), magnetic particle testing (MT), X-ray computed tomography (CT), and acoustic emission $(\mathrm{AE}) .^{16,17}$

Four-unit posterior FPDs are still indicated in cases where replacing missing teeth with implants is not possible; to maintain the periodontal health with short posterior abutments and reduced occlusal clearance, the connector's size is reduced. To the best of the authors' knowledge, insufficient research has been conducted regarding the effect of the framework design on chipping resistance in zirconia 4-unit FDPs. Moreover, the testing techniques mentioned above do not allow a live transmission and an absolute load value of the failures within the tested material. Therefore, a novel methodology, especially designed for this research, combined acoustic emission and visual monitoring during live load-bearing tests.

The aim of the present in vitro pilot study was to evaluate the influence of the connector area on the chipping rate of the VM9 veneering ceramic in 4-unit Y-TZP FDPs using a novel sonographic technique, testing the hypothesis that different connector dimensions affect the chipping rate of zirconia bilayered FDPs.

\section{Materials and Methods}

Twelve zirconia-based and three metal-based frameworks (five frameworks with a connector area of $7.5 \mathrm{~mm}^{2}$, five frameworks with a connector area of $8 \mathrm{~mm}^{2}$, and five frameworks with a connector area of $9 \mathrm{~mm}^{2}$ ) were fabricated, representing the study groups. Static loading was undertaken for all the specimens.

A master cast containing a mandibular first premolar and a mandibular second molar (abutments teeth) was prepared, according to the manufacturer's directives for zirconia-based all-ceramic crowns ( $1 \mathrm{~mm}$ chamfer finish line, 1 to $1.5 \mathrm{~mm}$ reduction). The distance between the two abutments was $23 \mathrm{~mm}$.

An impression of the abutment teeth was taken with a (poly) vinyl siloxane material (Express 3M ESPE). The impression was poured with GC Fujirock EP (Type 4 dental stone, GC Europe NV). The abutments were scanned in a CAD/CAM scanning unit (Kavo Everest Scan Pro Eco). The virtual 3D conception of the connectors was designed by a software (Energy CAD) and then transferred to a milling unit (Everest Engine). The zirconia-based copings were milled out of zirconium blanks (Kavo Everest BIO-ZS-Blank) and sintered in a high-temperature furnace (Kavo Everest Therm), according to the manufacturer's instructions. After sintering, all frameworks were seated on the cast, using Occlu PlusSpray (Hager \& Werken GmbH \& Co. KG), to ensure a good fit, and the thickness was measured with a caliper at four previously defined points.

A feldspathic ceramic Vita VM9 (VITA Zahnfabrik) was applied onto the zirconia copings. Two bonder firings, one base dentine firing, one liner firing, two dentine firings, and two glaze firing were performed and fired in a conventional 
ceramic furnace, according to the manufacturer's instructions.

Similar to the zirconia, three porcelain fused to metal (PFM) FDPs were fabricated. The metal frameworks were milled out of the resin C-Cast blocs (KAVO) and casted in nickel-chrome alloy (Super Alloy EX-3, Kuraray Noritake Dental Inc.). The metal copings were veneered with Vita VM13 (VITA Zahnfabrik). To produce comparable FDPs, a silicone impression was used to monitor the thickness of the veneered ceramic.

The abutment teeth were duplicated to form nickelchrome dies. A framework was temporarily glued over the dies (Cyanoacrylate adhesive). The specimen was inserted into a specimen holder, and a low-shrinkage, self-curing acrylic resin (SAMPL-KWICK, Buehler) was poured up to $3 \mathrm{~mm}$ below the gingival margin of the pontics.

\section{The Sonographic Test}

An audio-visual system including a high-sensitivity microphone, a sound amplifier, a sound analysis software, a movie camera, and a Windows Media Player software were needed for this purpose.

The microphone (Earthquake) was connected to a sound amplifier and held one centimeter away from the sample to allow the capture of the slightest noise. The amplifier itself was connected to a sound software (Protools), converting the sounds emitted by the specimens to a visual signal, called "wave," displayed on the computer screen. During the test, silence was assured to prevent external sound interferences.

Perpendicular to the screen, a digital video camera (Sony) mounted on a tripod was positioned 2 meters away from the computer screen. It filmed simultaneously, the peak movement of the wave displayed on the computer screen and the load value (Newton) displayed on the screen of the testing machine (-Fig. 1).

\section{Static Load-Bearing Test}

Static load-bearing test was conducted with a universal testing machine (Versa Test Mecmesim). A three-point

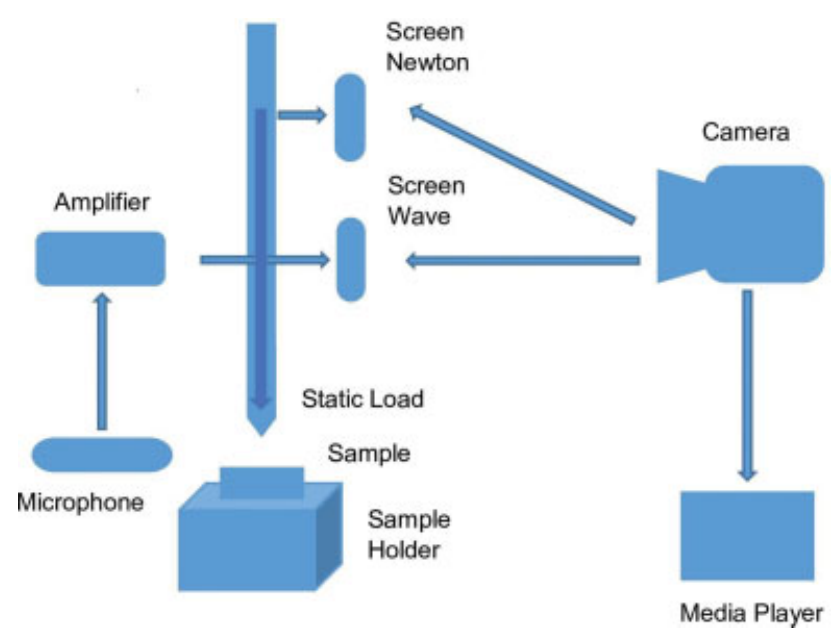

Fig. 1 Representation of the testing system 24 . contact between the indenter and the occlusal surface of the veneered zirconia framework was assured before loading.

Two rubber disks (1-mm thickness per disk) were interposed between the head of the indenter and the occlusal surface of the framework (mesial pit of the mandibular right first molar) to establish a homogeneous distribution of stresses and prevent contact damage (Hertzian damage). The rubber disks were replaced with new ones for each test.

The noncemented specimens were softly loaded to a predetermined force of $30 \mathrm{~N}$ approximately to eradicate the noise interference and ensure the stability of the specimens during the loading process. Afterward, the load meter was reinitialized, and the specimens were loaded until failure using a conical indenter with a $60^{\circ}$ cone angle, 1-mm diameter and $12-\mathrm{mm} / \mathrm{min}$ crosshead speed (minimal speed). The first wave is due to the sound of the power button, while the second wave represents the crack sound. A sudden increase/peak in the wave movement shows the failure of the sample, which dictate the interruption of the loading process, followed by the removal of the noncemented samples.

The specimens were then inspected using a digital microscope (Kappler Atslar Wetzlar) (25 times magnification) and photographed with a digital camera (Canon EOS 70D, Digital SLR, Canon) to identify failure modes. To determine the load value at the peak of the wave, in other words, the sample's resistance value to cracks chipping or fracture, the films recorded by the video camera were analyzed in a Windows Media Player software using the slow-motion option.

\section{Statistical Analysis}

SPSS computer software (SPSS 16.0, Inc; Chicago, IL) was used to analyze the data. The means and standard deviations (SD) of failure loads were compared. One-way ANOVA was used for statistical analysis, and Tukey HSD test was employed for comparisons. A significant difference is assumed to exist among the groups if the probability of such a difference is found to be $\leq 5 \%$ ( $p$-value $\leq 0.05$ ).

\section{Results}

Three modes of failure were observed: cohesive failures (fractures or cracks within the veneering layer) (-Fig. 2), adhesive failures (fractures or cracks separating the veneering layer from the zirconia core) (-Fig. 3), and core failures (fractures or cracks in the zirconia core) (-Fig. 4).
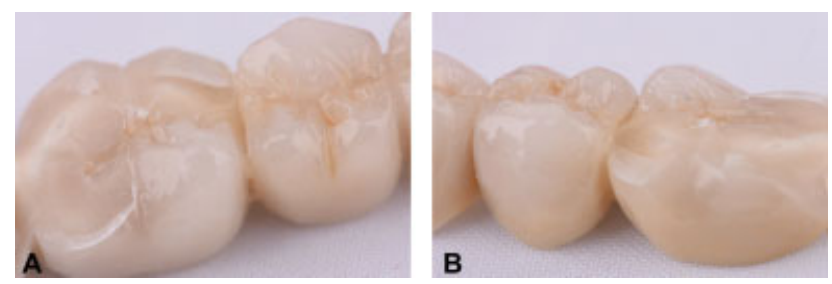

Fig. 2 Cohesive failures 24 . 


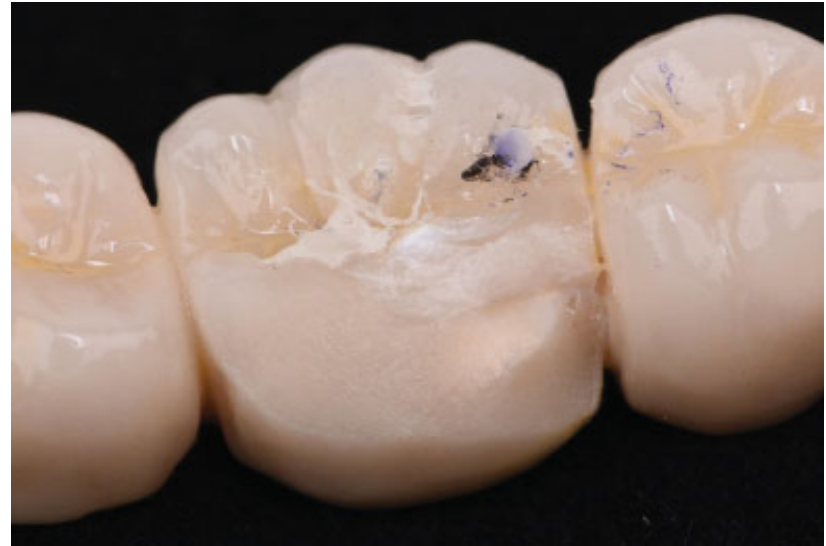

Fig. 3 Adhesive failure 25 .

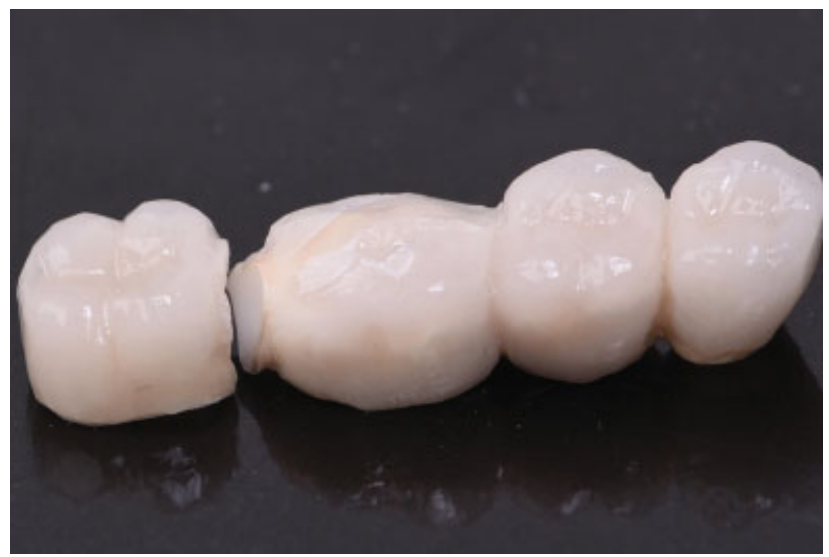

Fig. 4 Core failure 25.

The first group $\left(\mathrm{ZrO}_{2} ; 7.5 \mathrm{~mm}^{2}\right)$ demonstrated predominantly cohesive failures ( 3 cohesive failures), whereas the second group $\left(\mathrm{ZrO}_{2} ; 8 \mathrm{~mm}^{2}\right)$ demonstrated predominantly core failures ( 3 core failures), and the third group $\left(\mathrm{ZrO}_{2}\right.$; $9 \mathrm{~mm}^{2}$ ) demonstrated predominantly adhesive failures (3 adhesive failures). ( $\mathbf{- T a b l e ~} \mathbf{1}$ )

Failure loads were recorded for each specimen, and the means and SD were calculated for each group (-Table 2 ). The third group $\left(\mathrm{ZrO}_{2} ; 9 \mathrm{~mm}^{2}\right)$ demonstrated the highest failure load values among the study groups with a mean value of $978.375 \mathrm{~N}$ and a maximum value of $1155 \mathrm{~N}$. The first group $\left(\mathrm{ZrO}_{2} ; 7.5 \mathrm{~mm}^{2}\right)$ demonstrated the lowest failure load values with a mean value of $842.8 \mathrm{~N}$ and a maximum value of 975.7 N.

An analysis of the chipping load in relation to the crosssectional area of the connector revealed no significant differences $(p$-value $=0.185$ ) in chipping load, depending on the cross-sectional area.

Additionally, and regardless of the connector's size, the chipping strength of the ceramic VM13 on the nonprecious metal FDPs is significantly greater than that of the ceramic VM9 FDPs (Y-TZP) $(p$-value $<0.05)$ ( - Table 3 ).

\section{Discussion}

In the present study, load-bearing tests were conducted on 4unit FDPs designed to compensate the loss of two consecutive teeth in the mandible (second premolar and first molar).

The results of the load-bearing tests may be influenced by the mobility of the dies, the failure mode, the design of the framework, and cementation status. ${ }^{18}$ Lüthy et al suggested that immobile abutments generally lead to higher loadbearing capacities in comparison to mobile abutments and, therefore, leads to an overestimation of the clinical potential of the material. ${ }^{18}$ In the present study, $\mathrm{Ni}-\mathrm{Cr}$ abutments were adopted to avoid the distortion of the dies during the loading process, whereas immobile abutments were considered, since the specimens were not cemented over the dies. Several authors ${ }^{19,20}$ investigated clinically failed FDPs and found that no framework failed due to Hertzian or contact failure but from the gingival side at the connectors. Hence, rubber disks were placed on the occlusal surface of the pontics to avoid contact failure within the framework and distribute occlusal load.

The Kavo Everest CAD/CAM System was chosen for two reasons. First, the variety of materials it supports, including titanium, zirconium, plastic and glass ceramic blocks. Second, the use of a pioneering 5-axis milling and grinding technology. Furthermore, Kavo Everest BIO-ZS blanks were chosen due to its coefficient of thermal expansion (CTE) of $10.5 \times 10^{-6} / \mathrm{K}$, which is compatible with the CTE of VITA Zahnfabrik veneering glass ceramics $\left(9-9.5 \times 10^{-6} / \mathrm{K}\right)$, according to the manufacturer. ${ }^{21,22}$ Before veneering, a bonding agent (Effect Bonder VITA Zahnfabrik) was applied to the specimen surfaces and sintered according to the manufacturer's instructions. The Effect Bonder is recommended to improve the bond with Vita VM9 porcelain.

Table 1 Failure modes for the study groups after static loading

\begin{tabular}{|l|l|l|l|}
\hline Y-TZP & Group $\mathbf{1}\left(\mathbf{7 . 5} \mathrm{mm}^{\mathbf{2}}\right)$ & Group $\mathbf{2}\left(\mathbf{8} \mathrm{mm}^{\mathbf{2}}\right)$ & Group $\mathbf{3}\left(\mathbf{9} \mathrm{mm}^{2}\right)$ \\
\hline 1 & Core failure & Cohesive failure & Adhesive failure \\
\hline 2 & Cohesive failure & Core failure & Adhesive failure \\
\hline 3 & Cohesive failure & Core failure & Core failure \\
\hline 4 & Cohesive failure & Core failure & Adhesive failure \\
\hline PFM & Cohesive failure & Cohesive failure & Adhesive failure \\
\hline
\end{tabular}

Abbreviations: PFM, porcelain fused to metal; Y-TZP, yttria-stabilized tetragonal zirconia polycrystal. 
Table 2 Chipping loads (Newton) for the study groups

\begin{tabular}{|l|l|l|l|l|}
\hline \multicolumn{2}{|l|}{ Chipping loads (N) } & Group 1 & Group 2 & Group 3 \\
\hline \multirow{4}{*}{} & Connector dimension & $7.5 \mathrm{~mm}^{2}$ & $8 \mathrm{~mm}^{2}$ & $9 \mathrm{~mm}^{2}$ \\
\cline { 2 - 5 } & Sample size & 4 & 4 & 4 \\
\hline Y-TZP & Minimum & 654 & 743.3 & 840 \\
\cline { 2 - 5 } & Maximum & 975.7 & 1,105 & 1,155 \\
\cline { 2 - 5 } & Mean & 842.8 & 893.825 & 978.375 \\
\cline { 2 - 5 } & SD & 146.0859 & 151.7590 & 130.5267 \\
\cline { 2 - 5 } & Connector dimension & $7.5 \mathrm{~mm}^{2}$ & $8 \mathrm{~mm}^{2}$ & $9 \mathrm{~mm}^{2}$ \\
\hline \multirow{3}{*}{ PFM } & Sample size & 1 & 1 & 1 \\
\cline { 2 - 5 } & Mean & $1,228.2$ & 1,618 & 1,670 \\
\hline
\end{tabular}

Abbreviations: N, newton; PFM, porcelain fused to metal; SD, standard deviation; Y-TZP, yttria-stabilized tetragonal zirconia polycrystal.

Table 3 Chipping force difference between VM9 ceramic and VM13 ceramic for each connector

\begin{tabular}{|l|l|l|l|l|}
\hline \multicolumn{4}{|l|}{ Chipping forces (N) } \\
\hline $\begin{array}{l}\text { Connector } \\
\text { dimension } \\
\left(\mathrm{mm}^{2}\right)\end{array}$ & (I) Groups & (J) Groups & M (I-J) & $p$-Value \\
\hline 7.5 & Y-TZP & PFM & -385.400 & $0.039^{\text {a }}$ \\
\hline 8 & Y-TZP & PFM & -724.175 & $0.001^{\text {a }}$ \\
\hline 9 & Y-TZP & PFM & -691.625 & $0.002^{\text {a }}$ \\
\hline
\end{tabular}

Abbreviations: N, newton; PFM, porcelain fused to metal; Y-TZP, yttriastabilized tetragonal zirconia polycrystal.

a significant at $p \leq 0.05$.

In this study, the approach adopted for the veneering procedure was to produce identical FDPs to allow a reliable comparison between different groups. To standardize the layering veneering specimens, the veneering procedure of the zirconia copings was carefully guided by the silicone index. The specimens were not cemented over the $\mathrm{Ni}-\mathrm{Cr}$ dies, since they had to be removed for macroscopic examination. The lack of cementation can affect the absolute results in comparison to previously reported studies.

To determine the extent of the use of the veneered zirconia-based restorations to the posterior dentition, their performance has to be judged based on the mastication loads reported in that region. Loads range from 50 to $250 \mathrm{~N}$ during normal mastication, ${ }^{18}$ and 500 to $1,000 \mathrm{~N}$ in case of parafunctional behavior such as bruxism, depending on the measuring method, the location in the dentition, and the measuring device. $^{23}$

Regardless of the material, it is generally desired to increase the connector's cross-sectional area to enhance the longevity of a four-unit FDP restoration. Lüthy et al ${ }^{18}$ recommended a cross-sectional area of greater than $7.3 \mathrm{~mm}^{2}$ for clinical application. Therefore, in the present study, we adopted $7.5 \mathrm{~mm}^{2}, 8 \mathrm{~mm}^{2}$, and $9 \mathrm{~mm}^{2}$, and chipping load was measured in each different design.

Static loading provides the upper limit force a material can withstand before failure. ${ }^{24}$ To simulate the biting force on posterior teeth, an axial force was applied with a universal testing machine (Versa Test Mecmesim). The crosshead speed of the indenter $(12 \mathrm{~mm} / \mathrm{min})$ is considered a high speed for a load-bearing test. To capture the initiation of the fracture in the framework, despite the high crosshead speed, a dual sonographic system was adopted.

The specimens were preloaded to avoid the movement of the framework and eradicate the noise interference during the loading process. As a result of natural brittleness and inherent residual stress, the veneering porcelain of the zirconia-based restorations is subject to fracture. ${ }^{25}$ Although the chipping rates varied among the published studies, , 26-32 this complication was found in most of the investigations (-Table 4).

It is important to indicate that the present study focused exclusively on posterior 4-unit FDPs, while the majority of the FDPs reviewed in other studies were three units. According to Sax et al, ${ }^{26}$ a significant correlation of the span of the FDPs and the incidence of chipping was observed. A 4.9 times higher probability for chipping was found for 4- and 5-unit FDPs than for 3-unit FDPs. It has been demonstrated that chipping mostly occurred in premolars and molars, in connectors of mandibular posterior FDPs, and in second molars of FDPs. ${ }^{25,33,34}$ In addition, it has been reported that chipping occurred in nonload-bearing sites, such as the lingual side of FDPs $^{25-35}$ and the mesiolingual cusps of mandibular second molars. ${ }^{25-36}$

In the present investigation, zirconia FDPs recorded relatively high mean failure load values (842.8-978.375 N) compared with previous studies. This can be attributed to nonaged specimens. The third group $\left(9 \mathrm{~mm}^{2}\right)$ showed the highest failure load values, while the first group $\left(7.5 \mathrm{~mm}^{2}\right)$ showed the lowest failure load values.

Despite the fact that the chipping strength is proportional to the cross-sectional area of the connector, the effect of the cross-sectional area on chipping load revealed no significant differences. Therefore, the null hypothesis that different connector dimensions would affect the chipping load of FDPs was rejected. On the other hand, PFMs showed superior chipping strength relative to the zirconia frameworks, regardless of the size of the connector. 
Table 4 Clinical performance of zirconia all-ceramic restorations

\begin{tabular}{|l|l|l|l|l|l|}
\hline Authors & Mean time (years) & Type of restorations & Sample size & Failures & $\begin{array}{l}\text { Veneer porcelain } \\
\text { fracture }(\%)\end{array}$ \\
\hline Roediger et al $^{28}$ & 4 & $3-4$ unit FDPs & 99 & 13 & $13 \%$ \\
\hline Sax et al $^{26}$ & 10 & $3-5$ unit FDPs & 57 & 16 & $28 \%$ \\
\hline Schmitter et al & 5 & $4-7$ unit FDPs & 30 & 8 & $26.7 \%$ \\
\hline Schmitt et al $^{30}$ & 5 & $3-4$ unit FDPs & 25 & 7 & $28 \%$ \\
\hline Salido et al & 4 & 4 unit FDPs & 17 & 5 & $29.4 \%$ \\
\hline Rinke et al & 4 & $3-4$ unit FDPs & 80 & 23 & $28.8 \%$ \\
\hline Tartaglia et al & 72 & $1-6$ unit FDPs & 303 & 3 & $1 \%$ \\
\hline Norström Saarva et al & 3 & $2-8$ unit FDPs & 184 & 14 & $7.6 \%$ \\
\hline
\end{tabular}

Abbreviation: FDPs, fixed dental prostheses.

Moreover, catastrophic failure (core failure), which occurred in five frameworks, could be due to a high-loading speed, a defect in the zirconia core, or a stiff veneered ceramic. Analysis of catastrophic failure revealed that the distal connector was the site of fracture. This finding is similar to that in the report by Lüthy et $\mathrm{al}^{18}$ and Larsson et al. ${ }^{37}$ This may have been because the distance from the center of the distal abutment to the middle of the pontic was larger than the distance from the center of the mesial abutment to the middle of the pontic, as pointed out by Tsumita et al. ${ }^{38}$

This investigation is limited by the relatively small sample size as well as by the fact that this experimental study design did not imitate the conditions of the oral cavity, such as thermocycling or the dynamic forces of mastication.

\section{Conclusion}

Within the limitations of this pilot study, the following conclusions can be drawn:

1. The novel sonographic technique may be a potential method to study the behavior of dental ceramics, including chipping and fracture.

2. The effect of the cross-sectional area of 4-element Y-TZP posterior FDPs on chipping load revealed no significant differences.

3. Catastrophic fracture occurred at the distal connector between the pontic and the abutment corresponding to the second molar.

4. PFMs showed superior chipping strength relative to the zirconia frameworks.

5. Y-TZP FDPs have the potential to withstand the occlusal forces applied in the posterior region.

Further studies exploring different veneering ceramics, different veneering techniques, and dynamic loading will be needed to extend the present findings.

Conflict of Interest

None declared.

\section{References}

1 Raigrodski AJ, Hillstead MB, Meng GK, Chung KH. Survival and complications of zirconia-based fixed dental prostheses: a systematic review. J Prosthet Dent 2012;107(03):170-177

2 Sailer I, Gottnerb J, Kanelb S, Hammerle CH. Randomized controlled clinical trial of zirconia-ceramic and metal-ceramic posterior fixed dental prostheses: a 3-year follow-up. Int J Prosthodont 2009;22(06):553-560

3 Norström Saarva V, Bjerkstig G, Örtorp A, Svanborg P. A three-year retrospective study on survival of ceramic-veneered zirconia (YTZP) fixed dental prostheses performed in private practices. Int J Dent 2017;2017:9618306

4 Soares LM, Soares C, Miranda ME, Basting RT. Influence of coreveneer thickness ratio on the fracture load and failure mode of zirconia crowns. J Prosthodont 2017;28(02):209-215

5 Daou EE. The zirconia ceramic: strengths and weaknesses. Open Dent J 2014;8:33-42

$6 \mathrm{Kim} \mathrm{MJ}$, Oh SH, Kim JH, et al. Wear evaluation of the human enamel opposing different Y-TZP dental ceramics and other porcelains. J Dent 2012;40(11):979-988

7 Kou W, Molin M, Sjögren G. Surface roughness of five different dental ceramic core materials after grinding and polishing. J Oral Rehabil 2006;33(02):117-124

8 Anusavice KJ, Kakar K, Ferree N. Which mechanical and physical testing methods are relevant for predicting the clinical performance of ceramic-based dental prostheses? Clin Oral Implants Res 2007;18(Suppl 3):218-231

9 Koenig V, Vanheusden AJ, Le Goff SO, Mainjot AK. Clinical risk factors related to failures with zirconia-based restorations: an up to 9-year retrospective study. J Dent 2013;41(12):1164-1174

10 Mainjot AK, Schajer GS, Vanheusden AJ, Sadoun MJ. Influence of cooling rate on residual stress profile in veneering ceramic: measurement by hole-drilling. Dent Mater 2011;27(09):906-914

11 Mainjot AK, Schajer GS, Vanheusden AJ, Sadoun MJ. Influence of veneer thickness on residual stress profile in veneering ceramic: measurement by hole-drilling. Dent Mater 2012;28(02):160-167

12 De Lima E, Meira JBC, Özcan M, Cesar PF. Chipping of veneering ceramics in zirconium dioxide fixed dental prosthesis. Curr Oral Health Rep 2015;2:169-173

13 Ambré MJ, Aschan F, Vult von Steyern P. Fracture strength of yttria-stabilized zirconium-dioxide (Y-TZP) fixed dental prostheses (FDPs) with different abutment core thicknesses and connector dimensions. J Prosthodont 2013;22(05):377-382

14 Ha SR, Kim SH, Lee JB, Han JS, Yeo IS. Effects of coping designs on fracture modes in zirconia crowns: Progressive load test. Ceram Int 2016;42:7380-7389

15 Moráguez OD, Wiskott HW, Scherrer SS. Three- to nine-year survival estimates and fracture mechanisms of zirconia- and 
alumina-based restorations using standardized criteria to distinguish the severity of ceramic fractures. Clin Oral Investig 2015;19 (09):2295-2307

16 Fujita Y, Hamamoto Y. A robust automatic crack detection method from noisy concrete surfaces. Mach Vis Appl 2011;22:245-254

17 Domon H, Koshide S. Basis of Non-destructive Testing. Tokyo: Kbooks;1996:149-162

18 Lüthy H, Filser F, Loeffel O, Schumacher M, Gauckler LJ, Hammerle $\mathrm{CH}$. Strength and reliability of four-unit all-ceramic posterior bridges. Dent Mater 2005;21(10):930-937

19 Campbell SD, Sozio RB. Evaluation of the fit and strength of an allceramic fixed partial denture. J Prosthet Dent 1988;59(03): 301-306

20 Kelly JR. Clinical failure of dental ceramic structures: insights from combined fractography, in vitro testing and finite element analysis. Ceram Trans 1994;48:125-136

21 Vita Zahnfabrik. Vita Pm9 / Vita Vm9 Add-on Working instructions (Brochure). Bad Sackingen, Germany: Vita Zahnfabrik; 2009

22 Vita Zahnfabrik. Vita Vm9 Product Information (Brochure). Bad Sackingen, Germany: Vita Zahnfabrik; 2011

23 Takuma Y, Nomoto S, Sato T, Sugihara N. Effect of framework design on fracture resistance in zirconia 4-unit all-ceramic fixed partial dentures. Bull Tokyo Dent Coll 2013;54(03):149-156

24 Al-Wahadni A, Al-Saleh H, Al-Quran F, Hatamleh MM. Fracture resistance of fixed partial dentures supported by different abutment combinations: an ex vivo study. Gen Dent 2012;60(05): e295-e301

25 Ha SR, Kim SH, Lee JB, Han JS, Yeo IS, Yoo SH. Effects of coping designs on stress distributions in zirconia crowns: finite element analysis. Ceram Int 2016;42:4932-4940

26 Sax C, Hämmerle CH, Sailer I. 10-year clinical outcomes of fixed dental prostheses with zirconia frameworks. Int J Comput Dent 2011;14(03):183-202

27 Rinke S, Gersdorff N, Lange K, Roediger M. Prospective evaluation of zirconia posterior fixed partial dentures: 7-year clinical results. Int J Prosthodont 2013;26(02):164-171

28 Roediger M, Gersdorff N, Huels A, Rinke S. Prospective evaluation of zirconia posterior fixed partial dentures: four-year clinical results. Int J Prosthodont 2010;23(02):141-148
29 Salido MP, Martinez-Rus F, del Rio F, Pradies G, Ozcan M, Suarez MJ. Prospective clinical study of zirconia-based posterior fourunit fixed dental prostheses: four-year follow-up. Int J Prosthodont 2012;25(04):403-409

30 Schmitt J, Goellner M, Lohbauer U, Wichmann M, Reich S. Zirconia posterior fixed partial dentures: 5-year clinical results of a prospective clinical trial. Int J Prosthodont 2012;25(06): 585-589

31 Schmitter M, Mussotter K, Rammelsberg P, Gabbert O, Ohlmann B. Clinical performance of long-span zirconia frameworks for fixed dental prostheses: 5-year results. J Oral Rehabil 2012;39(07): 552-557

32 Tartaglia GM, Sidoti E, Sforza C. Seven-year prospective clinical study on zirconia-based single crowns and fixed dental prostheses. Clin Oral Investig 2015;19(05):1137-1145

33 Raigrodski AJ, Chiche GJ, Potiket N, et al. The efficacy of posterior three-unit zirconium-oxide-based ceramic fixed partial dental prostheses: a prospective clinical pilot study. J Prosthet Dent 2006;96(04):237-244

34 Tinschert J, Schulze KA, Natt G, Latzke P, Heussen N, Spiekermann $\mathrm{H}$. Clinical behavior of zirconia-based fixed partial dentures made of DC-Zirkon: 3-year results. Int J Prosthodont 2008;21(03): 217-222

35 Sailer I, Fehér A, Filser F, Gauckler LJ, Lüthy H, Hämmerle CH. Fiveyear clinical results of zirconia frameworks for posterior fixed partial dentures. Int J Prosthodont 2007;20(04):383-388

36 Schmitter M, Mussotter K, Rammelsberg P, Stober T, Ohlmann B, Gabbert O. Clinical performance of extended zirconia frameworks for fixed dental prostheses: two-year results. J Oral Rehabil 2009; 36(08):610-615

37 Larsson C, Holm L, Lövgren N, Kokubo Y, Vult von Steyern P. Fracture strength of four-unit Y-TZP FPD cores designed with varying connector diameter. An in-vitro study. J Oral Rehabil 2007;34(09):702-709

38 Tsumita M, Kokubo Y, Ohtsuka T, Nakamura Y, Fakushima S, Steyern PVV. Influences of core frame design on the mechanical strength of posterior all-ceramic fixed partial dentures. Part 1. Two-dimensional finite element analysis. Tsurumi Univ Dent J 2005;31:203-210 